\title{
Modification of Resolution in Capillary Electrophoresis for Protein Profiling in Identification of Genetic Modification in Foods ${ }^{\dagger}$
}

\author{
Anna Latoszek, ${ }^{a}$ Carmen García-Ruiz, ${ }^{\mathrm{b}}$ Maria Luisa Marina, ${ }^{\mathrm{b}}$ Francisco J. de la Mata, ${ }^{\mathrm{c}}$ Rafael \\ Gómez, ${ }^{\mathrm{b}}$ Beatriz Rasines, ${ }^{\mathrm{b}}$ Alejandro Cifuentes, ${ }^{\mathrm{d}}$ Ewa Poboży, ${ }^{\mathrm{a}}$ and Marek Trojanowicz ${ }^{\mathrm{a}, *}$ \\ ${ }^{a}$ Department of Chemistry, University of Warsaw, Pasteura 1, 02-093 Warsaw, Poland \\ ${ }^{\mathrm{b}}$ Department of Analytical Chemistry and Chemical Engineering, University of Alcalá, \\ 28871 Alcalá de Henares, Madrid, Spain

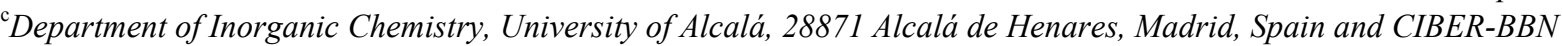 \\ ${ }^{\mathrm{d}}$ Department of Food Analysis, Institute of Fermentation Industry (CSIC), Juan de la Cierva 3, 28006 Madrid, Spain
}

\begin{abstract}
The capillary electrophoresis with UV detection was employed for protein profiling in extracts from maize and soybeans. Modifications of back-ground electrolyte and coating the capillary wall with polybrene was employed in order to decrease the protein adsorption on the capillary walls. The obtained protein profiles were compared for transgenic and non-transgenic variants, showing in some cases significant changes that might be employed for identification of genetic modifications of plants or foods of plant origin. (doi: 10.5562/cca1777)
\end{abstract}

Keywords: proteins, capillary electrophoresis, dendrimers, polybrene, GMO

\section{INTRODUCTION}

Production of foods from genetically modified organisms (GMO) is a source of great possibilities and large number of potential advantages. Plants of large economic and nutritional importance are mainly the subject of such modifications. The change of a genome is carried out in order to alter some features to ones more favorable for cultivating efficiency, better long-time storage properties and better resistance to herbicides, viruses, fungi and conditions of cultivation. Very often a target of genetic modification obtains better taste, color of fruits and nutritional values. ${ }^{1,2}$ The most commonly cultivated genetically modified (GM) plants are soy, maize and rape, as well as cotton, tobacco and potatoes. Their modified variants are commonly grown in many countries. ${ }^{3}$

The cultivation of genetically modified plants, and their use for the production of food for people is a source of numerous controversies. The origin of the fear for GMO's steams from lack of their fully documented safety regarding toxicity and allergic effects as well as their impact on natural environment, especially the possibility of non-controlled transfer of genes. ${ }^{4,5}$ In some countries both cultivation and use for food pro- duction is officially permitted, while in the other ones only supply to the market of GMO foods is permitted. In the European Union food products containing more than $0.9 \%$ GMO have to be labeled.

Nowadays detection of GMO in food products seems to be a very important task ${ }^{6}$ and most commonly it is carried out by the determination of particular DNA sequences or proteins specific for these organisms. ${ }^{7}$ For the determination of DNA fragments - the specific genes used in modifications - numerous techniques involving polymerase chain reaction (PCR) are commonly employed combined with different separation methods. ${ }^{8-10}$ Specific proteins can be determined immunochemically, ${ }^{11}$ with MALDI-TOF-MS measurements, ${ }^{12}$ or two-dimensional gel electrophoresis. ${ }^{13}$ The identification and determination of proteins is difficult due to their large number and variety, and also complex matrices of biological materials, therefore for this purpose both appropriate sample preparation as well as use of high performance separation methods is indispensable. For identification of GMO by determination of particular proteins or by comparison of protein profiles of extracts from examined samples, both HPLC and capillary electrophoresis can be used.

\footnotetext{
$\dagger$ Presented at the $10^{\text {th }}$ International Symposium and Summer School on Bioanalysis within the CEEPUS Network CII-HU-001004-0910, Zagreb, Croatia, July 2010.

* Author to whom correspondence should be addressed. (E-mail: trojan@chem.uw.edu.pl)
} 
Capillary electrophoresis (CE) is especially efficient separation method and commonly used for separation of proteins, including food extracts. ${ }^{14-16}$ Recently, there were several attempts to employ CE to obtain the protein profiles in extracts of maize and soybean, oriented towards finding some differences between genetically modified plant material or foods and natural variants and their food products. For this purpose both CE measurements with UV ${ }^{17,18}$ and MS detections ${ }^{19,20}$ were reported. Such studies were carried out for maize samples, ${ }^{18-20}$ as well soybean, ${ }^{17}$ of which GM variants are most commonly cultivated. It is well known that applied conditions of solvent extraction from plant material allow to extract different types of proteins. ${ }^{21,22}$

Zeins are the fraction of plant proteins analyzed most often. They are responsible for storage nitrogen for the developing seed. The extraction in investigation of maize samples was carried out with mixture of acetonitrile (ACN) and water with addition of 2-mercapto-ethanol (ME) and ammonia. ${ }^{19,20}$ For this purpose also watersoluble fraction (albumins) was used, ${ }^{18}$ while in case of soybean extracts the fraction extracted with $\mathrm{ACN} /$ water mixture with acetic acid. ${ }^{17}$ The CE measure-ments with UV detection were carried out using capillaries without any modification with borate back-ground electrolyte (BGE) with ACN addition for proteins extracted with ACN/water with acetic acid, ${ }^{17}$ while in case of albumins extracted with water several acidic BGEs were examined, assuming $0.2 \mathrm{~mol} \mathrm{dm}^{-3}$ solution of iminodiactetic acid of pH 2.26 was the optimum. ${ }^{18}$ For CE determination of zeins with MS detection the capillary was modified with ethylpyrrolidine methacrylate- $N, N$-dimethylacrylamide, ${ }^{19,20}$ and in both these cases BGE used was a mixture of $\mathrm{ACN}$, isopropanol, formic acid and water.

In case of profiling zeins by CE with TOF-MS detection in maize extracts carried out for 3 natural maize line and their corresponding transgenic lines, no significant differences were observed. ${ }^{20}$ In the earlier work, in similar conditions of extraction and electrophoretic separation with MS detection, there were also not observed any significant differences in terms of zein content between non-transgenic and transgenic variants. However some differences were observed between different lines of conventional maize. ${ }^{19}$ In analysis of water-soluble albumins from Bacillus thuringiensis-transgenic insect resistant and non-transgenic maize species by $\mathrm{CE}$ with UV detection at $206 \mathrm{~nm}, 2$ to 3 differences were found in recorded profiles in magnitude of signal or its absence in one of variants. ${ }^{18}$ In case of application of $\mathrm{CE} / \mathrm{UV}$ to differentiation of diverse transgenic and non-transgenic soybean varieties, by applying discriminant analysis using several protein peak areas as variable, some successful differentiation between transgenic and nontransgenic soybeans was reported based on measurements at 254 and $280 \mathrm{~nm} .^{17}$ These detection wavelengths cor- respond to the maximum absorption of certain common amino acids present in proteins.

Because of complex matrices of plant extracts and presence of numerous proteins, even with such efficient separation technique as capillary electrophoresis, a satisfactory separation is difficult to achieve. The additional problem to solve in separation of proteins is their common adsorption on capillary walls, which significantly deteriorates the efficiency of separation. In order to minimize this behavior various modifications of capillary walls ${ }^{15,23}$ or additions of different surface active species to BGE ${ }^{24}$ are used. One type of additives to BGE used to suppress adsorption of proteins are different polymers modifying the capillary walls and also altering electrophoretic properties of analytes. ${ }^{25}$

Design and synthesis of different nanostructures currently is highly discussed issue and an interesting subject of research in different areas of modern science and technology. They can be applied for different purposes in analytical chemistry. ${ }^{26,27}$ Various nanomaterials have already been employed as modifiers in chromatographic separations, ${ }^{26}$ and capillary electrophoresis. ${ }^{26,28}$ Dendrimers can be also a group of materials employed for this purpose. ${ }^{23}$ They are also known as unimolecular micelles and are highly symmetric three-dimensional structures, originally referred to as cascade molecules, and composed of initiator core, and repeating units with branching and terminal functional groups. ${ }^{29}$ They exhibit numerous interesting properties, such as e.g. space gaps in their structure can be used for transport of drugs. $^{30}$ Their most attractive advantages are unique structure and possibility of chemical modification of both their skeleton and surface. ${ }^{30,31}$ Dendrimers are synthesized in precisely controlled reactions composed of three stages, where new structure layers are formed on the surface leading to consecutive new generation of dendrimers. Each new surface layer bears double increase of electric charge, and it has almost a doubled molecular weight compared to initial structure.

For capillary electrophoresis, so far most widely investigated are polyaminoamide dendrimers, which are commercially available. In pioneering work their different generations were employed for separation of benzene and naphthalene derivatives. ${ }^{32}$ They can also be applied as pseudostationary phases for separation of hydrophobic solutes such as aromatic amino acids and catacholamines. ${ }^{33}$

Above citations of works on application of $\mathrm{CE}$ for obtaining protein profiles of extracts from plant materials indicate the potential possibility of application of $\mathrm{CE}$ for identification of genetic modifications of plants and foods. The reported results are not fully reliable, because of significant effect of numerous experimental parameters on reproducibility and informative content of such protein profiles. Results of such measurements 
are affected by type of protein fraction used for this purpose, and possible presence of various metabolites, conditions of separation and detection, as well as the content of GMO in examined model samples. The aim of this study was to examine effect of different modifications of CE separation for recorded protein profiles of maize and soybean extracts using UV detection. As modifiers of separation, two kinds of dendrimers will be employed with carbon and silicon cores as additives to the BGE, and also modification of capillary walls with polybrene.

\section{EXPERIMENTAL}

\section{Apparatus}

Part of work with silicon-based dendrimers as BGE modifiers was carried on HP3DCE system (Agilent Technologies, Waldbronn, Germany) equipped with oncolumn diode array detector (DAD). Instrument control and data acquisition was performed by the HP3DCE ChemStation software. Separation were performed on untreated fused-silica capillaries of $50 \mu \mathrm{m}$ ID and 375 OD with a total length of $48,5 \mathrm{~cm}$ and effective length of $40 \mathrm{~cm}$ from Composite Metal Services (Worcester, England, UK). The cassette temperature was set at $25^{\circ} \mathrm{C}$. Injections were made by pressure: $5 \mathrm{kPa}$ for $5 \mathrm{~s}$.

Experiments with dendrimers with amine core as BGE modifiers and Polybrene as capillary modificator were performed on Beckman-Coulter P/ACE MDQ CE system (Fullerton, CA, USA) with PDA detector. The CE instrument was controlled by a PC running System software from Beckman. Separations were carried out using fused-silica capillary (Polymicro Technologies. L. L. C., Phoenix, USA) of $51 \mathrm{~cm}$ total length $(40 \mathrm{~cm}$ effective length) and $75 \mu \mathrm{m}$ I.D. Capillary was thermostated in 25 C. Samples were injected by pressure: $3.4 \mathrm{kPa}$ for $5 \mathrm{~s}$.
All analysis were made by triplicate. Separation was at an electric field of $+/-20 \mathrm{kV}$. Detection was carried out at 214,254 at $280 \mathrm{~nm}$.

\section{Chemicals and Samples}

All reagents employed for the preparation of the samples and separation buffers were of analitycal grade. 85 $\%$ phosphoric acid, HPLC grade acetonitrile (ACN), methanol and $n$-propanol and ammonium acetate were from Merck (Darmstadt, Germany) and triethanolamine, 2-mercaptoethanol, ethanol and glacial acetic acid were supplied from Sigma Aldrich (Steinheim, Germany). All solutions were prepared with ultrapure water from Milli-Q system (Millipore, Bedford, MA, USA).

Polybrene (Hexadimethrine bromide) was from Sigma Aldrich (Steinheim, Germany).

Dedrimers with silica core were synthesized at Faculty of Inorganic Chemistry, University of Alcala, Alcala de Henares, Spain. Nine dendrimers were used in optimization of method:

- D8I - first generation dendrimer with iodide counter-ion,

- D16I - second generation dendrimer with iodide counter-ion,

- D32I - third generation dendrimer with iodide counter-ion,

- $\mathrm{D} 8 \mathrm{Cl}$ - first generation dendrimer with chloride counter-ion,

- $\mathrm{D} 16 \mathrm{Cl}$ - second generation dendrimer with chloride counter-ion,

- $\mathrm{D} 32 \mathrm{Cl}$ - third generation dendrimer with chloride counter-ion,

- D8TFS - first generation dendrimer with trifluoromethylsulfonic counter-ion,

- D16TFS - second generation dendrimer with trifluoromethylsulfonic counter-ion,

Table 1. Standards and samples of plant materials and food used in this study

\begin{tabular}{cclc}
\hline & \multicolumn{1}{c}{ ORIGIN } & GMO / NON-GMO \\
\hline \multirow{2}{*}{ SAMPE } & & NN \\
& SPI & Soya Isolated Protein (ICN, Aurora, Ohio, USA) & NN \\
& SA & SOJA AMARILLA - EL GRANERO, from local shop in Spain & NN \\
& SB & SOJA BLANCA - LUZ DE VIDA, from local shop in Spain & NN \\
& GM & Corn Gluten Meal (Sigma-Aldrich) & NO-GMO \\
& 1 ARISTIS from Estación Experimental Agrícola Mas Badía in & Tallada d'Empordá (Girona, Spain) & GMO \\
& 43 ARISTIS BT11 from Estación Experimental Agrícola Mas Badía in & NN \\
M3T & Tallada d' Empordá (Girona, Spain) & $0 \%$ GMO \\
MS0 & Maize Flour BIO, from ecological shop in Warsaw & GMO Standard ERM-BF412, Maize Bt-11, 0 \% Bt-11 (Sigma-Aldrich) & $5 \%$ GMO \\
\hline
\end{tabular}

$\mathrm{NN}$ - not known, whether examined sample contains GMO. 
- D32TFS - third generation dendrimer with trifluoromethylsulfonic counter-ion.

Dendrimers with amine core were from Sigma Aldrich (Schnelldorf, Niemcy):

- Dendrimer PAMAM $25 \%$ - C12, second generation,

- Dendrimer poly[propyleneimine] tetraammonium $\mathrm{DAB}-\mathrm{AM}-4$, first generation.

Standards and samples of plant materials and food used in this study are presented in Table 1. To prepare Aristis maize (wild type and its Bt11 transgenic variety) kernels and commercially available soya samples were separately milled to a fine powder using different grinders.

\section{Procedures}

Capillary Preparation

Capillary, before first run, was conditioned with sodium hydroxide $1 \mathrm{~mol} \mathrm{dm}^{-3}$ for $15 \mathrm{~min}$, water $-2 \mathrm{~min}$, hy-

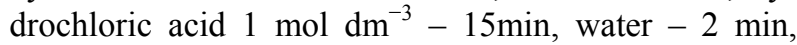
separation buffer $-30 \mathrm{~min}$.

Between different sample injection capillary was flushed with ortho-phosphoric acid $85 \%$ for $8 \mathrm{~min}$. Between injections capillary was flushed with BGE solution for $8 \mathrm{~min}$.

In analysis with dendrimers, capillary was flushed for $100 \mathrm{~min}$ with solution of BGE with dendrimers and after 5 injections for $40 \mathrm{~min}$.

It's important to notice, that during optimalization of conditions to every generation of dendrimers a new capillary was used to avoid any errors, correlated with interactions or capillary-stucking with dendrimers.

Modification of capillary with Polybrene was performed by flushing of capillary with $5 \%$ solution of Polybrene for $60 \mathrm{~min}$, when capillary was prepared for the first time; and for $30 \mathrm{~min}$ between new day of experiments.

\section{Sample Preparation}

Proteins from maize and soybean were extracted with ACN/water mixture containing $0.3 \%$ acetic acid. ${ }^{17} 100$ $\mathrm{mg}$ of each flour was mixed with $1 \mathrm{~mL}$ of extraction solvent, then the sample was vigorously shaken for 2 min and centrifuged for $20 \mathrm{~min}$. The supernatant was used for analysis.

\section{RESULTS AND DISCUSSION}

\section{Dendrimers with Amine Core as BGE Modifiers}

Dendrimers have been already employed as pseudostationary phases in CE measurements for obtaining protein profiles, allowing to tune the selectivity and resolution of separation. ${ }^{34}$ It was also shown in the literature that polycationic dendrimes are strongly adsorbed on capillary walls. ${ }^{35}$ From a large offer of commercially available dendrimers for experiments with modification

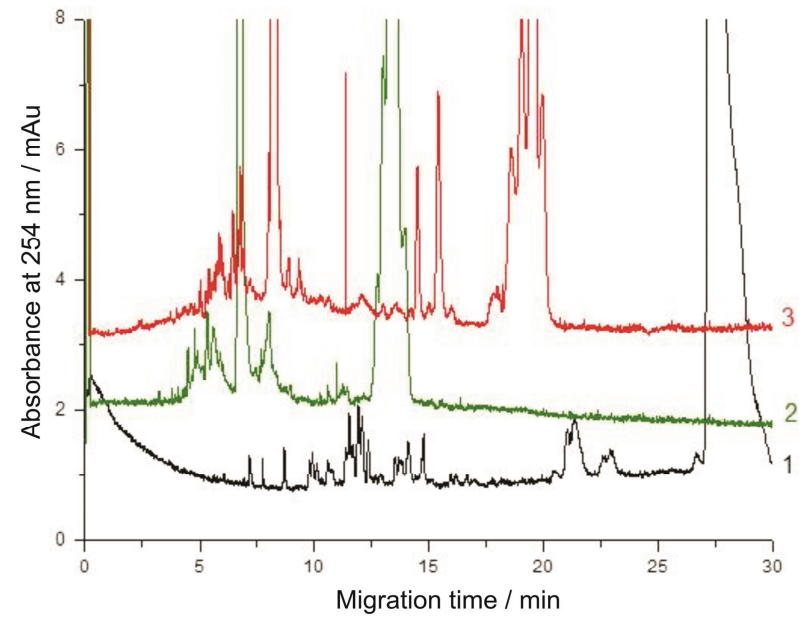

Figure 1. Effect of concentration of DAB dendrimer added to $\mathrm{BGE}$ on resolution of $\mathrm{CE}$ protein profiling of soybean $\mathrm{SB}$ extract. Sample $100 \mathrm{mg}$ extracted with ACN:water mixture (25:75) containing $0.3 \%$ acetic acid. BGE: $80 \mathrm{mM}$ phosphate buffer of $\mathrm{pH} 2.5$ containing $5 \% \mathrm{ACN}$ and DAB Dendrimer in different concentration: $(1-0,001 \%, 2-0,01 \%, 3-0,05 \%)$. Separation at $-20 \mathrm{kV}$, detection at $254 \mathrm{~nm}$.

of BGE the poly[propyleneimine] tetraammonium dendrimer generation 1.0 (DAB) was employed, and as model plant material for obtaining protein profile a commercially available soybean (SB) was employed. The soybean sample was extracted with ACN/water mixture containing $0.3 \%$ acetic acid which was already employed earlier for differentiation of various commercial soybeans. ${ }^{17}$ In case of formerly used borate BGE for application with dendrimer additive too long migrations were observed for practical measurements. The phosphate buffer of low $\mathrm{pH}$ value was already employed for $\mathrm{CE}$ of water soluble proteins, ${ }^{18}$ and in this work was employed with addition of DAB dendrimer and $5 \%$ of ACN. As it is illustrated by electropherograms in Figure 1 , in the presence of larger content of DAB, numerous signals are recorded in electropherogram. Taking into account large number of relatively strong signals recorded, the 0.01 to $0.05 \%$ content of DAB in BGE was assumed as optimum. Whole protein profile was recorded in about $20 \mathrm{~min}$, and for $0.05 \%$ content of DAB in BGE a slightly better reproducibility of recordings was observed.

In case of soybeans, because of lack of sample with known genetic modification, the comparison of protein profiles was carried out for sample of isolated proteins, and extracts from two kinds of soybeans available in local market in Spain. Both, extraction conditions and conditions of CE measurement were the same as mentioned above. In recorded electropherograms (Figure 2) there is no significant difference in number of recorded signals, but for main signals recorded with good reproducibility of migration times the 


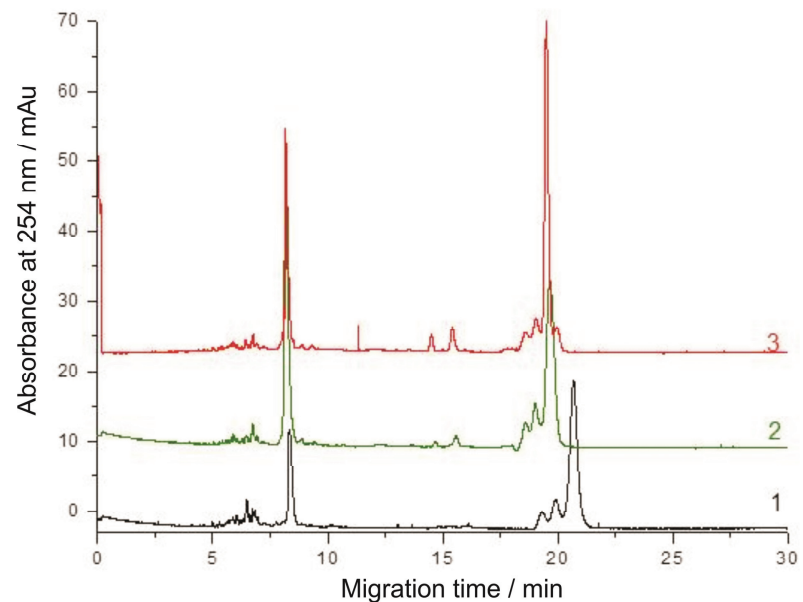

Figure 2. Comparison of separation results for different soybean samples: SPI (1), SA (2) and SB (3) using BGE with $0,05 \%$ of DAB dendrimer. Sample $100 \mathrm{mg}$ extracted with ACN:water mixture (25:75) containing $0.3 \%$ acetic acid. BGE: $80 \mathrm{mM}$ phosphate buffer of $\mathrm{pH} 2.5$ containing $5 \% \mathrm{ACN}$ and $0,05 \%$ DAB Dendrimer. Separation at $-20 \mathrm{kV}$, detection at $254 \mathrm{~nm}$

magnitude of signals is evidently different. A larger content of selected proteins in extracts from commercial soybeans may potentially be caused by genetic modification.

Similar measurements were carried out for extracts maize gluten standard from Sigma and also for samples of maize ARISTIS natural and modified Bt11 variant. For these samples some changes in profile of zein proteins were reported earlier in CE/MS measurements, where ACN/water extraction was made with addition of ME and ammonia, ${ }^{19}$ although the result of other similar studies was negative. ${ }^{20}$ Differences in protein profiles of those variants were also observed in CE/UV measurements for aqueous extracts. ${ }^{18}$ Figure 3 shows electropherograms of extracts from maize samples M3 and M3T, and for comparison also for gluten extract, where for the same sensitivity of detection any similar signals were observed. For GM variant the increase of selected signals, which was earlier reported for numerous signals obtained in different conditions of sample extraction and CE separation. ${ }^{18}$

The UV detection is quite often employed for protein profiling both in capillary electrophoresis and HPLC. Sometimes detection is performed around 254 or $280 \mathrm{~nm}$, where the aromatic residues have absorption bands, but most often at 200-220 nm, where the absorption is proportional to the number of peptide bonds. This detection is popular because no derivatization is needed; it is quantitative, simple, and readily available. The UV detection at $214 \mathrm{~nm}$ was employed by many authors for protein profiling, see e.g. Ref. 24. Practically, no differences were found for extracts of maize standard samples from Fluka without and with $5 \%$ transgenic maize at

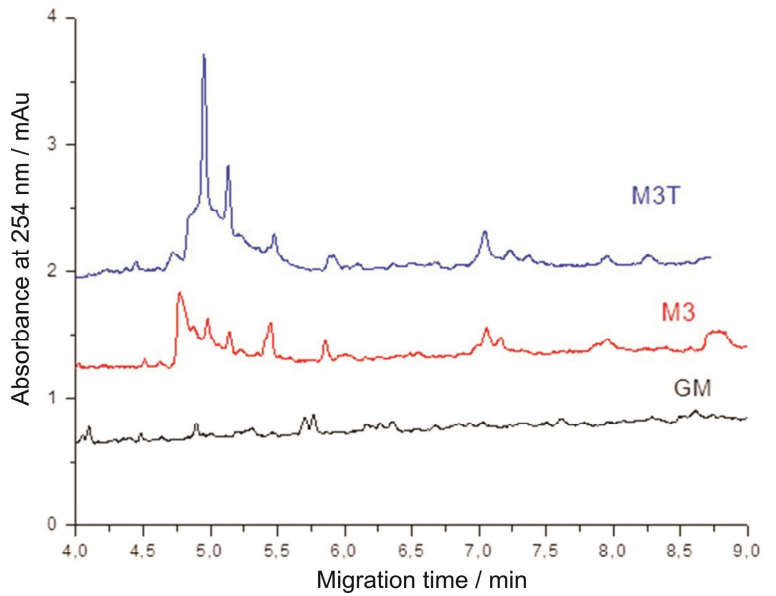

Figure 3. Differentiation between maize samples: gluten (GM), non-modified (M3) and genetically modified modified (M3T). Sample: 50(GM) or 100(M3 and M3T) mg extracted with ACN:water mixture (25:75) containing $0.3 \%$ acetic acid. BGE: $80 \mathrm{mM}$ phosphate buffer of $\mathrm{pH} 2.5$ containing $5 \% \mathrm{ACN}$ and $0,01 \% \mathrm{DAB}$ Dendrimer. Separation at $-20 \mathrm{kV}$, detection at $254 \mathrm{~nm}$.

both wavelength of detection 214 and $254 \mathrm{~nm}$. (MS0 and MS50).

Besides dendrimer DAB, as another modifier the dendrimer with carbon core, poly(amideamino) dendrimer of generation 2 PAMAM 25\%-C12 with etylenediamine was employed. In CE measurements of maize M3 extract the obtained electropherogram did not contain larger number of signals than with $\mathrm{DAB}$, and it was not used for further experiments.

\section{Silicon-based Dendrimers as BGE Modifiers}

These dendrimers were laboratory synthesized for present applications in 3 generations and with different counter-ions. Their application was investigated with model maize samples extracted in the same procedure as reported above for measurements with amine core dendrimers in BGE. For extract of sample M3 the electropherograms with $80 \mathrm{mmol} \mathrm{dm}^{-3}$ borate BGE of $\mathrm{pH} 2.0$, containing $5 \% \mathrm{ACN}$ ands $0.01 \%$ of various dendrimers content were recorded. For smaller content of dendrimers the electropherograms recorded within $20 \mathrm{~min}$ exhibit smaller number of protein signals for the same extract. The generation of dendrimer (D8 - $1^{\text {st }}$, D16 $2^{\text {nd }}, \mathrm{D} 32-3^{\text {rd }}$ ) is not of a significant importance for number of signals in recorded protein profiles (Figure 4 ), although the lower the generation of dendrimer, the less stable is base-line, which probably can be attributed to electrophoretic mobility of dendrimer. For further experiments the second generation dendrimer was used.

It was already reported in the literature, that the conformation of dendrimer molecule depends on size of counter-ion, ${ }^{36}$ which may affect seriously its adsorption 


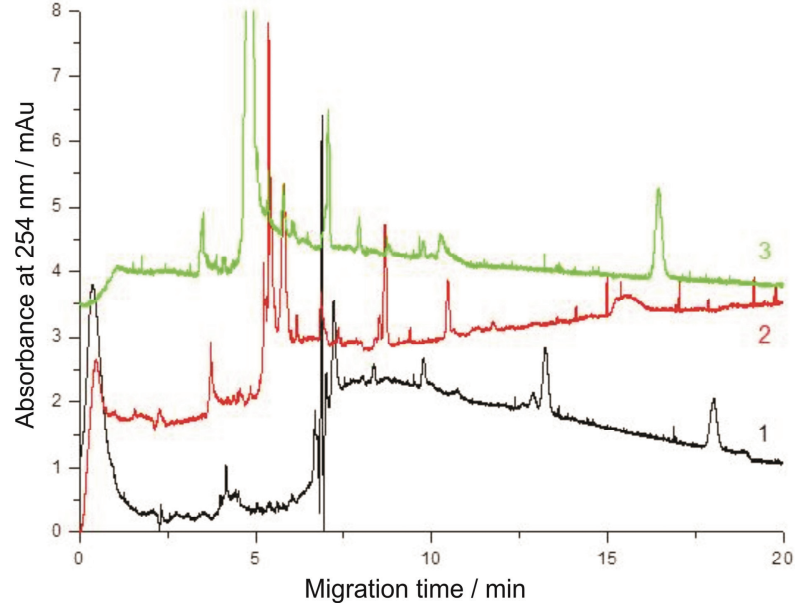

Figure 4. Effect of generation of dendrimer with iodide counter-ion added to BGE on resolution of CE protein profiling of maize M3 extract. Sample $300 \mathrm{mg}$ extracted with ACN:water mixture $(25: 75)$ containing $0.3 \%$ acetic acid. BGE: $80 \mathrm{mM}$ phosphate buffer of $\mathrm{pH} 2.0$ containing $5 \% \mathrm{ACN}$ and $0,01 \%$ Dendrimer $\left(1-\mathrm{D} 8-1^{\text {st }}\right.$ generation, $2-\mathrm{D} 16-2^{\text {nd }}$ generation, $3-\mathrm{D} 32-3^{\text {rd }}$ generation). Separation at $-20 \mathrm{kV}$, detection at $254 \mathrm{~nm}$.

on the wall of capillary. In order to examine this effect electropherograms were recorded with the dendrimer of the same generation in BGE but with different counterions. It was found that counter-ion does not exhibit evident difference in number of recorded signals as it is showed in Figure 5 for dendrimers with chloride $(\mathrm{D} 16 \mathrm{Cl})$, iodide (D16I) and trifluoromethylsulfonate (D16TFS). For further measurements D16I was taken, as with D16TFS too short migration times were observed, while with $\mathrm{D} 16 \mathrm{Cl}$ they were too long. The coun-

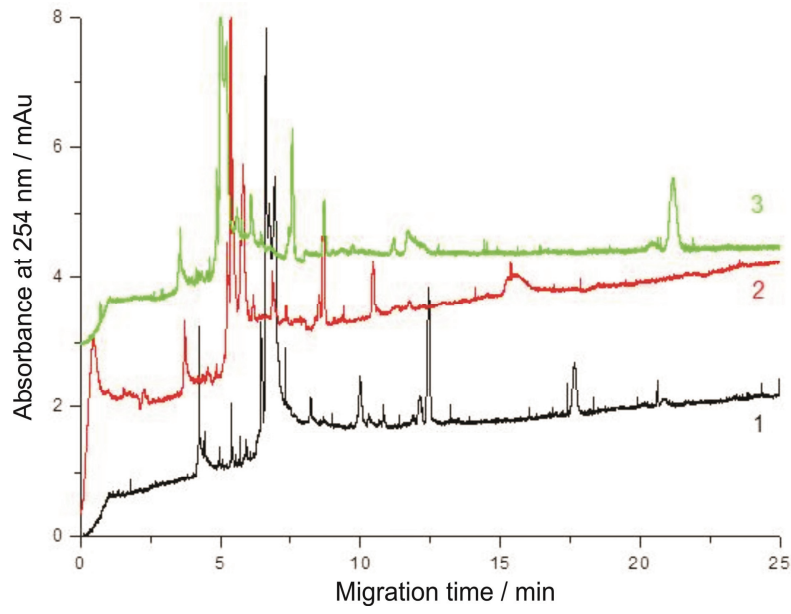

Figure 5. Effect of counter-ion of dendrimer added to BGE on resolution of CE protein profiling of maize M3 extract. Sample $300 \mathrm{mg}$ extracted with ACN:water mixture (25:75) containing $0.3 \%$ acetic acid. BGE: $80 \mathrm{mM}$ phosphate buffer of $\mathrm{pH} 2.0$ containing $5 \% \mathrm{ACN}$ and $0,01 \%$ Dendrimer $(1-\mathrm{D} 16 \mathrm{Cl}, 2$ D16I, 3 -D16TFS). Separation at $-20 \mathrm{kV}$, detection at $254 \mathrm{~nm}$. ter-ion employed in a given dendrimer preparation affects its interaction with separated proteins. A significantly longer migration times were observed for decrease of dendrimer content in BGE, hence content 0.01 $\%$ was assumed as optimum. The effect of concentration of phosphate in BGE was examined in the range 40 to $80 \mathrm{mmol} \mathrm{dm}^{-3}$, and no significant differences were found. The $80 \mathrm{mmol} \mathrm{dm}{ }^{-3}$ concentration was selected because of obtaining most stable current intensity during measurements. The effect of $\mathrm{pH}$ of BGE was examined in the range 2.0 to 3.0 , and value $\mathrm{pH} 2.5$ was assumed as optimum.

It is know that in $\mathrm{CE}$ the separation efficiency can be affected by addition of organic solvent to BGE, hence in these studies effect of addition of methanol, ethanol, $n$-propanol, iso-propanol and acetonitrile was examined. For both propanols results were similar, and for $20 \%$ content of other solvents in BGE the best separation efficiency were found for ethanol and $\mathrm{ACN}$, and for the latter solvent obtained migration times were shorter. From examined range of concentration of ACN in BGE from 5 to $20 \%$, the shortest migration times, and the best resolution was found for $5 \%$ content.

In such optimized experimental conditions for $\mathrm{CE}$ measurements, the comparison of protein profiles for non-transgenic (M3) and transgenic maize extracts was carried out, and obtained electropherograms are shown in Figure 6. Similarly to the results of measurements with the BGE containing DAB dendrimer (Figure 3), also in this case some reproducible differences were noted, namely a decrease of magnitude of peak 1 , and lack of peak 4 in electropherograms from extracts of the transgenic sample. Those difference in protein profiles

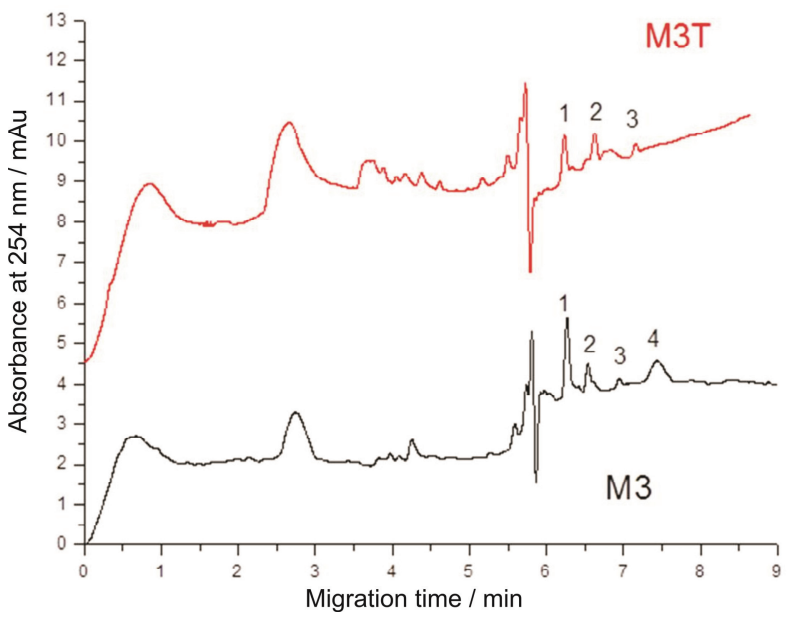

Figure 6. Differentiation between maize samples: nonmodified (M3) and genetically modified modified (M3T). Sample $300 \mathrm{mg}$ extracted with ACN:water mixture (25:75) containing $0.3 \%$ acetic acid. BGE: $80 \mathrm{mM}$ phosphate buffer of $\mathrm{pH} 2.5$ containing $5 \% \mathrm{ACN}$ and $0,01 \%$ Dendrimer D16I. Separation at $-20 \mathrm{kV}$, detection at $254 \mathrm{~nm}$. 


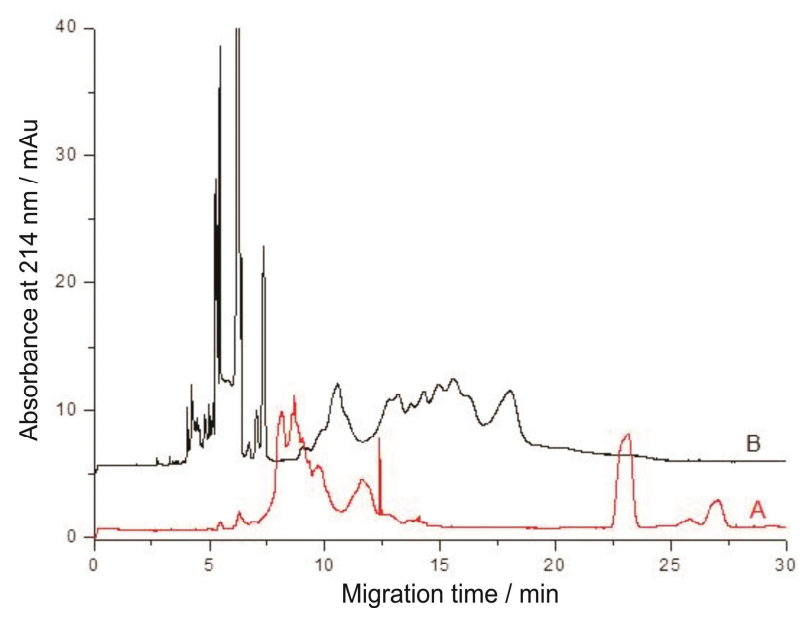

Figure 7. Effect of capillary modification with solution of Polybrene on resolution of CE protein profiling of soybean SB extract. Sample $100 \mathrm{mg}$ extracted with ACN:water mixture (25:75) containing $0.3 \%$ acetic acid. BGE: $50 \mathrm{mM}$ phosphate buffer of $\mathrm{pH}$ 2.5. A - uncoated capillary, B - capillary coated with $5 \%$ solution of Polybrene. Separation on uncoated capillary: $20 \mathrm{kV}$; Separation on coated capillary: $-20 \mathrm{kV}$, detection at $214 \mathrm{~nm}$.

can be explained only by genetic modification, due to the fact, that analyzed samples (M3 and M3T) were grown under the same field conditions.

\section{Modification of Capillary Wall with Polybrene}

Application of physically adhered polymers is widely employed for CE separation of proteins. ${ }^{42}$ Polybrene (hexadimetrine bromide) can be deposited on capillary wall by rinsing the capillary with the polymer solution. The stability of coating and reproducibility of electroosmotic flow (EOF) in coated capillary depends strongly on composition of BGE, and its $\mathrm{pH}$. In investigation of different BGEs in this study it was found that stable EOF can be obtained using $50 \mathrm{mmol} \mathrm{dm}^{-3}$ phosphate buffer of $\mathrm{pH} 2.5$. For such BGE, for soybean SB extract prepared in the same way as in above reported experiments, effect of polybrene coating was examine. For the coating with $5 \%$ polybrene solution a much more advantageous electropherogram was obtain compared to that one obtained of non-coated capillary, with large number of strong signals (Figure 7). In measurements of maize MM extracts a satisfactory reproducibility of recorded electrophero- grams was obtain, however it was less satisfactory for soybean extracts. Practically, the same results were obtained using detection with wavelength of 214 and $254 \mathrm{~nm}$.

In the same condition of extraction with ACN/water containing $0.3 \%$ acetic acid, the protein profiles were recorded for soybean samples SA and SB, and also for isolated soybean proteins (Figure 8). Similarly, to the reported above $\mathrm{CE}$ measurements with BGE

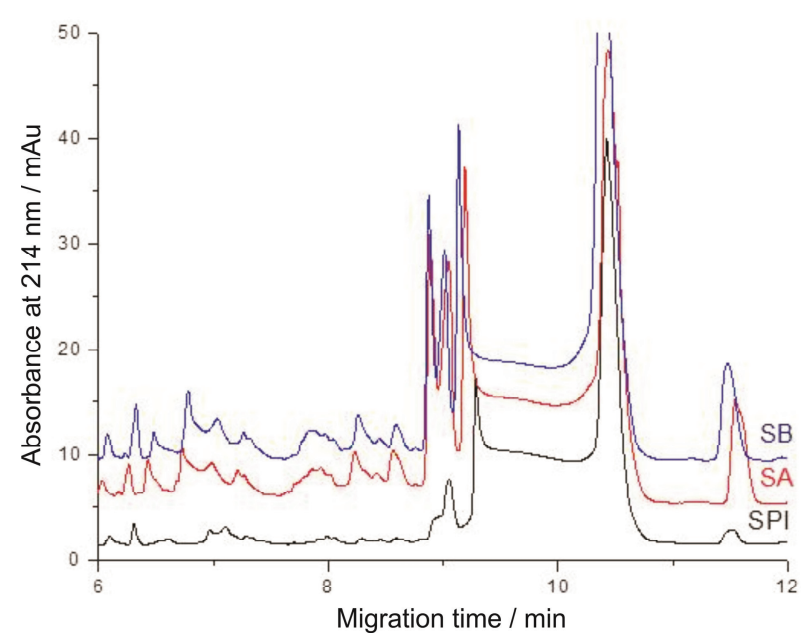

Figure 8. Comparison of separation results for different soybean samples: SPI, SA and SB using capillary coated with Polybrene. Sample $100 \mathrm{mg}$ extracted with ACN:water mixture (25:75) containing $0.3 \%$ acetic acid. BGE: $50 \mathrm{mM}$ phosphate buffer of $\mathrm{pH} 2.5$. Separation at $-20 \mathrm{kV}$, detection at $214 \mathrm{~nm}$.

containing dendrimer DAB (Figure 2), the pronounced difference were found between soybean samples and isolated soybean proteins. Again, it can be interpreted as effect of genetic modification of commercial soybean samples, but at this stage it can only be a hypothesis. It should also be taken into account that these differences may result from some differences in technological processing of examined materials affecting e.g. the efficiency of extraction, and they should be confirmed using other methods. Similar distinct differences of protein profiles were observed earlier for natural and transgenic variants of soybean obtained in CE/UV measurements in different conditions. ${ }^{17}$

\section{CONCLUSION}

CE measurements carried in these studies with background electrolytes modified with dendrimers, or capillary wall modified with polybrene, show some differences in protein profiles for extracts obtained for transgenic and non-transgenic variants of maize and soybean. Both ways of applied modifications of capillary electrophoretic resolution are helpful to decrease the effect of protein adsorption, and allow to obtain stable baseline and reproducibility of migrations times. Among employed modifications of BGE with dendrimers or coating capillary wall with polybrene, the latter method seems to be more appropriate providing better reproducibility and more pronounced differences in protein profiles. The observed differences in analyzed samples show some potential possibilities of application of this concept for identification of GMO, which is consistent with some earlier works using HPLC ${ }^{37-39}$ and CE measurements ${ }^{17-20}$ of protein profiles. However, this should 
be confirmed in detail using some reference methods $\left(\mathrm{PCR}^{40,41}\right.$ or protein immunoassays) and much larger number of samples in order to obtain statistically significant data, and also some information about possible quantification aspects of such measurements. So far, the main obstacle in such studies is difficulty in obtaining model samples of different GMO variants, even for the most commonly cultivated maize or soybean.

Acknowledgements. This study was party supported by Polish Ministry of Science, grant No. N N204 014936. Anna Latoszek thanks ERSMUS Program for financing her study visit to University of Alcala.

\section{REFERENCES}

1. J. Luthy, Food Control 10 (1999) 359-361.

2. E. Venneria, S. Fanasca, G. Monastra, E. Finotti, R. Ambra, E. Azzini, A. Durazzo, M. S. Foddai, and G. Maiani, J. Agric. Food Chem. 56 (2008) 9206-9214.

3. D. Bowles and H. Klee, Plant J. 27 (2001) 481-482.

4. P. Celec, M. Kukuckova, V. Renczesova, S. Natarajan, R. Palffy, R. Gardlik, J. Hodosy, M. Behuliak, B. Vlkova, G. Minarik, T. Szemes, S. Stuchlik, and J. Turna, Biomed. Pharmacotherapy 59 (2005) 531-540.

5. H. A. Kuiper and G. A. Kleter, Trends Food Sci. Technol. 14 (2003) 277-293.

6. M. Trojanowicz, A. Latoszek, and E. Poboży, Anal. Lett. 43 (2010) 1653-1679.

7. H. Y. Lin, J. W.Chiang, and D. Y. C. Shih, J. Food Drug Anal. 9 (2001) 160-166.

8. L. Sanchez, R. Gonzalez, A. L. Crego, and A. Cifuentes, J. Sep. Sci. 30 (2007) 579-585.

9. V. García-Cañas, R. González, and A. Cifuentes, Trends Anal. Chem. 23 (2004) 637-643.

10. A. Nadal, A. Coll, J. L. La Paz, T. Esteve, and M. Pla, Electrophoresis 27 (2006) 3879-3888.

11. A. Roda, M. Mirasoli, M. Guardigli, E. Michelini, P. Simoni, and M. Magliulo, Anal. Bioanal. Chem. 384 (2006) 1269-1275.

12. W. R. Adams, S. S. Huang, A. L. Kriz, and M. H. Luethy, J. Agric. Food Chem. 52 (2004) 1842-1849.

13. M. C. Ruebelt, N. K. Leimgruber, M. Lipp, T. L. Reynolds, M. A. Nemeth, J. D. Astwood, K. H. Engel, and K. D. Jany, J. Agric. Food Chem. 54 (2006) 2154-2177.
14. G. L. Erny, M. L. Marina, and A. Cifuentes, Electrophoresis 28 (2007) 2988-2997.

15. V. Dolnik, Electrophoresis 27 (2006) 126-141.

16. A. Cifuentes, Electrophoresis 27 (2006) 283-303.

17. C. Garcia-Ruiz, M. C. Garcia, A. Cifuentes, and M. L. Marina, Electrophoresis 28 (2007) 2314-2323.

18. P. Sazelova, V. Kasicka, E. Ibanez, and A. Cifuentes, J. Sep. Sci. 32 (2009) 3801-3808.

19. G. L. Erny, M. L. Marina, and A. Cifuentes, Electrophoresis 28 (2007) 4192-4201.

20. G. L. Erny, C. Leon, M. L. Marina, and A. S. Cifuentes, J. Sep. Sci. 31 (2008) 1810-1818.

21. T. B. Osborne, J. Am. Chem. Soc. 19 (1897) 525-532.

22. F. A. Monamy, D. J. Sessa, J. W. Lawton, and G. W. Selling, J. Agric. Food Chem. 54 (2006) 543.

23. V. Dolnik, K. M. Hutterer, Electrophoresis 22 (2001) 4163-4176.

24. S. R. Bean, G. L. Lookhart, and J. A. Bietz, J. Agric. Food Chem. 48 (2000) 318-327.

25. Ch. P. Palmer, J. Chromatogr. A 780 (1997) 75-92.

26. E. Guihen and J. D. Glennon, Anal. Lett. 36 (2003) 3309-3336.

27. M. Trojanowicz, Trends in Anal. Chem. 25 (2006) 480-489.

28. Ch. Nilsson and S. Nillson, Electrophoresis 27 (2006) 76-83.

29. U. Boas and M. H. Heegaard, Chem. Soc. Rev. 33 (2004) 43-63.

30. K. Sadler and J. P. Tam, Rev. Mol. Biotechnol. 90 (2002) 195-229.

31. I. Gitsov and C. Lin, Curr. Org. Chem. 9 (2005) 1025-1051.

32. N. Tanaka, T. Tanigawa, K. Hosoya, K. Kimata, T. Araki, and S. Terabe, Chem. Lett. 6 (1992) 959-962.

33. H. Gao, J. Carlson, A. M. Stalcup, and W. R. Heineman, J. Chrom. Sci. 36 (1998) 146-154.

34. C. Stathakis, E. A. Arriaga, and N. J. Dovichi, J. Chromatogr. A 817 (1998) 233-238.

35. A. Ebber, M. Vaher, J. Peterson, and M. Lopp, J. Chromatogr. A 949 (2002) 351-358.

36. T. Terao, Mol. Phys. 104 (2006) 2507-2513.

37. J. M. Rodriguez-Nogales, M. C. Garcia, and M. L. Marina, J. Sep. Sci. 29 (2006) 197-210.

38. J. M. Rodriguez-Nogalez, A. Cifuentes, M. C. Garcia, and M. L. Marina, Food Chem. 111 (2008) 483-489.

39. M. C. Garcia, B. Garcia, C. Garcia-Ruiz, A. Gomez, A. Cifuentes, and M. L. Marina, Food Chem. 113 (2009) 1212-1217.

40. I. Taverniers, P. Windels, M. Vaitilingom, A. Milcamps, E. Van Bockstaele, G. Van den Eede, and M. De Loose, J. Agric. Food Chem. 53 (2005) 3041-3052.

41. M. Onishi, T. Matsuoka, T. Kodama, K. Kashiwaba, S. Futo, H. Akiyama, T. Maitani, S. Furui, T. Oguchi, and A. Hino, J. Agric. Food Chem. 53 (2005) 9713-9721.

42. H. Stutz, Electrophoresis 30 (2009) 2032-2061. 